OPEN ACCESS

Edited by:

Martin Jastroch,

Helmholtz Zentrum München,

Germany

Reviewed by:

Jens Mittag,

University of Lübeck, Germany

Dmitry Zaretsky,

Intarcia Therapeutics, Inc.

United States

Miklós Székely,

Medical School, University of Pécs,

Hungary

*Correspondence:

Carola W. Meyer

carola.meyer@mpi-bn.mpg.de

Specialty section:

This article was submitted to Integrative Physiology,

a section of the journal

Frontiers in Physiology

Received: 20 May 2017 Accepted: 06 July 2017

Published: 31 July 2017

Citation:

Meyer CW, Ootsuka Y and

Romanovsky AA (2017) Body

Temperature Measurements

for Metabolic Phenotyping in Mice.

Front. Physiol. 8:520.

doi: 10.3389/fphys.2017.00520

\section{Body Temperature Measurements for Metabolic Phenotyping in Mice}

\author{
Carola W. Meyer ${ }^{1 *}$, Youichirou Ootsuka ${ }^{2}$ and Andrej A. Romanovsky ${ }^{3}$ \\ ${ }^{1}$ Department of Pharmacology, Max-Planck Institute for Heart and Lung Research, Bad Nauheim, Germany, ${ }^{2}$ Centre for \\ Neuroscience, School of Medicine, Flinders University of South Australia, Adelaide, SA, Australia, ${ }^{3}$ FeverLab, St. Joseph's \\ Hospital and Medical Center, Phoenix, AZ, United States
}

Endothermic organisms rely on tightly balanced energy budgets to maintain a regulated body temperature and body mass. Metabolic phenotyping of mice, therefore, often includes the recording of body temperature. Thermometry in mice is conducted at various sites, using various devices and measurement practices, ranging from single-time probing to continuous temperature imaging. Whilst there is broad agreement that body temperature data is of value, procedural considerations of body temperature measurements in the context of metabolic phenotyping are missing. Here, we provide an overview of the various methods currently available for gathering body temperature data from mice. We explore the scope and limitations of thermometry in mice, with the hope of assisting researchers in the selection of appropriate approaches, and conditions, for comprehensive mouse phenotypic analyses.

Keywords: mouse, phenotyping, body temperature, thermography, metabolism, telemetric recordings, mouse models

\section{KEY POINTS}

- Rectal probing is subject to procedural bias. This method is suitable for first-line phenotyping, provided probe depth and measurement duration are standardized. It is also useful for detecting individuals with out-of-range body temperatures (during hypothermia, torpor).

- The colonic temperature attained by inserting the probe $>2 \mathrm{~cm}$ deep is a measure of deep (core) body temperature.

- IR imaging of the skin is useful for detecting heat leaks and autonomous thermoregulatory alterations, but it does not measure body temperature.

- Temperature of the hairy or shaved skin covering the inter-scapular brown adipose tissue can be used as a measure of BAT thermogenesis. However, obtaining such measurements of sufficient quality is very difficult, and interpreting them can be tricky. Temperature differences between the inter-scapular and lumbar areas can be a better measure of the thermogenic activity of inter-scapular brown adipose tissue.

- Implanted probes for precise determination of BAT temperature (changes) should be fixed close to the Sulzer's vein. For measurement of BAT thermogenesis, core body temperature and BAT temperature should be recorded simultaneously.

- Tail temperature is suitable to compare the presence or absence of vasoconstriction or vasodilation.

- Continuous, longitudinal monitoring of core body temperature is preferred over single probing, as the readings are taken in a non-invasive, physiological context.

- Combining core body temperature measurements with metabolic rate measurements yields insights into the interplay between heat production and heat loss (thermal conductance), potentially revealing novel thermoregulatory phenotypes. 


\section{INTRODUCTION}

Precise phenotyping of mice strains and genetically modified mice has become increasingly important for revealing correlations and inferring causality amongst specific physiological pathways. Important targets in mouse phenotyping include changes in energy balance, which can result in altered body composition (Tschöp et al., 2012; Rozman et al., 2014). The majority of studies targeting energy balance involve measurements of body mass, fat mass, and food (energy) intake (Moir et al., 2016). Many authors also report energy expenditure by using indirect calorimetry (Speakman, 2013; Meyer et al., 2015). In addition, body temperature is often measured.

At present, mouse body temperature data for metabolic phenotyping is mainly obtained by one of three methods: (1) inserting a probe into the rectum (or, less typically, into the sigmoid colon); (2) measuring temperature in the abdominal cavity or in the subcutaneous compartment with a pre-implanted probe; or (3) measuring surface temperature with infrared (IR) thermography (e.g., from the tail, trunk areas, external auditory meatus, or eyes). In many cases, thermometry data obtained by any of these methods is presented as a single (often the mean) value labeled "body temperature." Unfortunately, this simplistic approach ignores the fact that the body of a mouse is thermally heterogeneous - and that all sites produce different output values. For example, IR thermography of a mouse tail provides information about the vasomotor tone of the tail vasculature, whereas colonic thermometry produces a value of deep body temperature. This creates a need for the appropriate labeling of temperature data. Condensing complex data into a single mean value also dismisses the pronounced circadian rhythms of body temperature in mice and, in general, ignores the fact that body temperature is constantly affected by changes in both the external and internal environments (Gordon, 1993).

We think that the method of thermometry (i.e., where and how body temperature is measured) and the experimental conditions (e.g., ambient temperature, whether or not the animals are restrained, and whether or not they are acclimated to the experimental setups and procedures) are of enormous importance for the interpretation of any body temperature data obtained during metabolic phenotyping of genetically modified mice. Below, we overview the main methods used for thermometry at different sites of the body in the mouse (with occasional reference to the rat) and address the utility of these methods in the context of mouse metabolic phenotyping.

\section{Rectal (or Colonic) Thermometry}

Rectal thermometry is a common method of measuring body temperature in rodents. It involves inserting a small-diameter temperature probe through the anus. The temperature-sensitive element of the probe is either a thermistor, a resistance temperature detector (RTD), or the "hot" (active) junction of a thermocouple (Box 1). As the core of the body is warmer than the shell, the body temperature value obtained with a rectal probe critically depends on the insertion depth. In adult mice, an insertion depth of $>2 \mathrm{~cm}$ will yield colonic temperatures. In fact, the temperature measured by this method is one of highest temperatures in the body of endotherms, corresponding to deep (core) body temperature (Donhoffer, 1980).

Less-deep insertion of the probe results in somewhat lower and more variable readings, corresponding to rectal temperatures. Despite the fact that rectal temperature is somewhat inferior to colonic temperature; it is still a valid measure. Rectal thermometry is the simplest, and sometimes lowest-cost, method for obtaining body temperature data in conscious mice. It is also the lowest-impact method, as the procedure is fast and painless for mice, and no surgery is required. To obtain a rectal temperature, the mouse is usually hand-restrained and placed on a horizontal surface, e.g., a cage lid. The tail is then lifted, and a probe (covered with Vaseline) is gently inserted into the rectum to a fixed depth (typically, up to $2 \mathrm{~cm}$ ). Although different laboratories and manufacturers recommend different insertion depths, it is critical that the depth be exactly the same for each measurement to reduce withingroup variability. For comparative purposes, insertion depth should be routinely reported in publications involving rectal thermometry.

The time of rectal readings depends on the time constant of the probe and is often specified by the manufacturer. If the reading is taken too fast, the value obtained underestimates the real temperature. However, waiting too long may also create a problem as body temperature increases rapidly (i.e., within seconds) as part of the stress response of the mouse to being

\section{BOX 1 | Thermocouples, thermistors, and RTDs.}

A thermocouple is formed by two dissimilar metals. The voltage produced by such a junction is temperature-dependent. Different types of thermocouples use different metal combinations and, therefore, have different characteristics. By convention, the color of the thermocouple connector identifies the type. For most physiological purposes, including rectal thermometry, copper-constantan (T-type) thermocouples are used; their plugs are usually made of blue plastic. The response time of these temperature probes is often around $0.5 \mathrm{~s}$, but it can vary widely based on the probe size and insulating materials used. The accuracy of thermocouple probes can be rather high $\left(<0.1^{\circ} \mathrm{C}\right)$, but in most commercially available devices for rectal thermometry, it is somewhere between 0.1 and $0.5^{\circ} \mathrm{C}$.

Thermistors and the so-called RTDs (resistance temperature detectors) are used to measure temperature because their electrical resistance depends on temperature. Thermistors are generally made from certain metal oxides, often incased in ceramic, and their resistance decreases with increasing temperatures. RTDs are made of metals, such as platinum and nickel, and their resistance increases with temperature. In general, RTDs have technical characteristics that are superior to those of thermistors and thermocouples, but these minor technical differences are of little relevance to the typical tasks of rectal thermometry in mice. RTDs are also more expensive.

The material of the probe shaft is relevant when environmental parameters are significantly deviating from physiological, i.e., during cold exposure. If the metal holder of the probe is short, it is able to transfer energy to the sensor, hence pushing the readings toward cooler values in cold. In this case, non-metal shafts are preferred in order to reduce bias. 
handled and fixated (Clement et al., 1989). Hence, rectal body temperature readings obtained at longer time periods are more likely to be "contaminated" by stress hyperthermia. Acute stressinduced increases in body temperature can be greatly alleviated if the mice are trained to the measurement procedure and to restraint (Garami et al., 2011). Rodents are readily adaptable to confinement, and-when habituated-incur neither a stress fever (Romanovsky et al., 1998) nor show any other signs of stress (Hashimoto et al., 1988; Melia et al., 1994; Stamp and Herbert, 1999).

Rectal probing is particularly useful in diagnosing body temperatures outside the normal range, e.g., during conditions of torpor and hypothermia (Haemmerle et al., 2006). Provided that variations in probe depth, mouse age and sex, as well as other factors impacting body temperature are controlled for, rectal thermometry can also be used for first-line phenotyping of cohorts of genetically modified mice (Willershäuser et al., 2012). Because the method is prone to environmental and procedural variations (Zethof et al., 1994), it is more useful for screening for large effects on body temperature rather than for studying mechanisms of effects on body temperature - especially if the effects are moderate or small. Assuming an insertion depth of $2 \mathrm{~cm}$ and a standard deviation of $0.4^{\circ} \mathrm{C}$ for inbred C57BL/6J mice (Willershäuser et al., 2012), detecting a moderate difference of $0.5^{\circ} \mathrm{C}$ in rectal temperature at $p<0.05$ and a power of $80 \%$ (two-sided $t$-test) would require the use of at least 12 animals per group.

\section{Wireless Measurements of Body Temperature Using Implanted Probes}

Wireless monitoring of temperature can be achieved using probes that are firmly anchored to the inside of the body to obtain temperature data from freely-moving, conscious animals. Table 1 gives an overview of the current products available for measuring internal temperatures in unrestrained mice and other small mammals. Some of the probes not only provide temperature readings, but also enable the measurement of gross motor activity. The devices listed are transmitters, transponders and data loggers (Boxes 2-4). In addition, novel implantable transponder-logger hybrids have been made available to enable the identification and monitoring of multiple animals in one cage (see Table 1). This relieves the constraint to house animals individually for measuring body temperature, thus allowing for no-contact thermometry in a social context.

Owing to their size, miniature transponders, e.g., IPTT300, are typically implanted subcutaneously. They represent advanced versions of animal identification chips and, as such, provide subcutaneous temperature measurements as an "added bonus." At most locations (e.g., on the back of the animal), the subcutaneous temperature determined by a transponder will be close to the temperatures of the adjacent hairy (non-glabrous) skin (Romanovsky, 2014). Subcutaneous temperatures can vary widely and are strongly affected by the ambient temperature. They cannot serve as a measure of deep body temperature.

In some mouse studies, miniature transponders are implanted in proximity to the inter-scapular brown adipose tissue (BAT) depots (e.g., Bal et al., 2012; Gerhart-Hines et al., 2013; Muller et al., 2013; Lateef et al., 2014). Although some of these studies claim successful use of such implants for assessing the (change in) temperature of BAT (as a measure of thermogenic activity), we are skeptical about such applications and do not recommend them - considering the rather large size of the transponder in relation to the BAT tissue. There are also some technical concerns: when thermogenesis in BAT is activated, the generated heat is collected throughout the brown fat pads by venous blood and leaves the tissue through Sulzer's vein (Smith and Horwitz, 1969). The amount of heat generated is so high that it is sufficient to rapidly warm the entire body of an animal by a few degrees Celsius. Hence, in active BAT, a proper measurement of brown fat temperature is substantially (sometimes by more than $1^{\circ} \mathrm{C}$ )

TABLE 1 | Temperature probes for measuring body temperatures in unrestrained mice.

\begin{tabular}{|c|c|c|c|c|c|c|}
\hline Product name & Type & Mass (g) & $\begin{array}{l}\text { Volume } \\
\left(\mathrm{cm}^{3}\right)\end{array}$ & $\begin{array}{l}\text { Simultaneous acquisition } \\
\text { in multiple animals }\end{array}$ & $\begin{array}{l}\text { Average battery } \\
\text { life }^{d} \text { (months) }\end{array}$ & $\begin{array}{l}\text { Manufacturer } \\
\text { URL }\end{array}$ \\
\hline DSI PhysioTel TA-F10 & Transmitter & 1.6 & 1.1 & No & 6 & www.datasci.com \\
\hline Anipill & Transmitter & 1.7 & 1.2 & Yes & 7 & www.datasci.com \\
\hline E-Mitter Series 3000 XM-FH ${ }^{\mathrm{C}}$ & Transponder & 1.6 & 1.1 & No & Battery-free & $\begin{array}{l}\text { http://www.minimitter.com/ } \\
\text { www.respironics.com }{ }^{a}\end{array}$ \\
\hline G2 E- Mitter ${ }^{\mathrm{C}}$ & Transponder & 1.1 & 0.6 & No & Battery-free & www.starrlifesciences.com ${ }^{b}$ \\
\hline IPTT-300 & Transponder & 0.1 & 0.1 & No & Battery-free & www.bmds.com \\
\hline SubCue Mini & Logger & 2.5 & 1.5 & Yes & 30 & www.subcue.com \\
\hline DST nano-T & Logger & 1.0 & 0.5 & Yes & 14 & www.star-oddi.com \\
\hline DST nano RF-T & Transponder-logger & 1.3 & 0.6 & Yes & 12 & www.star-oddi.com \\
\hline XS Stellar telemetry ${ }^{\mathrm{C}}$ & Transponder-logger & 2.5 & 1.5 & Yes & 5 & www.tse-systems.com \\
\hline Mouse Monitor ${ }^{\mathrm{TM}}$ C19BTAC & Transponder-logger & 2.7 & 1.9 & Yes & 0.5 rechargeable & www.indusinstruments.com \\
\hline
\end{tabular}

a This product is no longer commercially available, but is still used in some laboratories.

bIn 2013, STARR Life Sciences (international distributor: Harvard Apparatus Ltd) acquired the VitalView/E-Mitter product line from Philips Respironics.

${ }^{c}$ This product also collects information on gross motor activity.

${ }^{d}$ Battery life depends on sampling frequency. Battery-free devices require no refurbishment. Their maximal lifetime is variable (usually $>2$ years). 


\section{BOX 2 | Transponders.}

A transponder is an electronic device that can receive radiofrequency signals in response to predetermined signals. Hence, it can function as both a transmitter and a responder. If used for animal identification purpose, its function is to send out an identifier signal when an outside signal requests identification. A transponder consists of a coil antenna coupled to an integrated circuit chip, both covered by biocompatible glass or plastic. For temperature-measuring transponders, the chip includes a thermistor to measure temperature and a memory unit to store temperature data. An example of a transponder, IPTT-300, is listed in Table 1. This is a low-accuracy $\left(0.5^{\circ} \mathrm{C}\right)$ device used mostly in large-scale animal husbandry operations, where some rough estimate of body temperature is obtained "for free" along with the animal's identifier. A main advantage of transponders is the ease of their implantation (using a syringe-like injector) and their battery-free operation. Once implanted, a transponder can provide temperature data for the entire life of the animal.

\section{BOX 3 | Telemetry transmitters.}

A transmitter is an electronic device that generates and amplifies a carrier wave, modulates it according to its temperature, and broadcasts the resulting signal from an antenna. Signal modulation by temperature is typically achieved through changes in either the frequency (frequency modulated, FM) or the amplitude (amplitude modulated, AM). For implantable transmitters used to measure body temperature, all the electronics involved in sensing temperature, modulating and transmitting the signal are hidden inside a miniature biocompatible capsule. Several examples of transmitters are listed in Table $\mathbf{1}$. Their accuracy is generally greater than $0.2^{\circ} \mathrm{C}$. For those experimental conditions where a radio signal from a transmitter implanted in an animal can be easily detected by a receiver, transmitter-based telemetry is often a method of choice for real-time thermometry.

\section{BOX 4 | Data loggers.}

A temperature data logger is an electronic device that stores temperature signals in digital form on silicon or wax-coated memory chips integrated with a temperature probe. The device is programmed and implanted into an animal. The temperature information can be read only after the logger is removed from the animal, which usually happens at the end of the experiment when the animal is euthanized. The sampling frequency is set during programming, and the amount of data that can be stored and retrieved depends on the memory size. For example, if the memory size is 2,000 data points, the logger can store the data for $\sim 1.4$ days of recordings at 1-min sampling, or for about 85 days of recordings at 1-h sampling. The major advantage of data loggers is that they can be used under those conditions that do not permit communication between a transmitter and receiver, e.g., in a field experiment, or when an animal is placed in an environment impermeable to radio waves, such as in some designs of a thermogradient apparatus (Almeida et al., 2006; Garami et al., 2011).

higher than core body temperature, as was shown in rats with thermocouples acutely implanted in the inter-scapular depots of brown fat immediately before an experiment (Szekely et al., 1973; Szekely and Szelenyi, 1979), and in some experiments using chronic implantation techniques (Romanovsky et al., 1997; Ootsuka et al., 2007; Almeida et al., 2012). In chronic experiments, it is difficult to achieve the quality of measurements that would allow one to accurately quantify this phenomenon. To achieve a high-quality BAT temperature measurement, a probe must be fixed in the immediate proximity of Sulzer's vein with special techniques (e.g., Almeida et al., 2012; and Figure 1).

Even when a probe is properly positioned near Sulzer's vein, BAT temperature can be influenced by temperature changes in the muscles underneath the BAT depots, and in the skin above. To control for these influences, at least partially, it is important to measure core body temperature at the same time. The difference between BAT and core body temperature, sometimes referred to as "BAT themogenic index," can be used to assess BAT heat production (Almeida et al., 2012). Comparing the slope of an increase in BAT temperature during the initial phase of BAT thermogenesis with the slope of core body temperature is a way to assess the validity of BAT temperature measurements (Mohammed et al., 2014).

Most often, the probes listed in Table 1 are implanted into the peritoneal cavity to measure what is commonly referred to as "abdominal temperature." Abdominal temperature is a valid measure of deep (core) body temperature. The associated surgical intervention involves a small midline incision through the skin, followed by an opening of the peritoneal cavity through the linea alba. In order to prevent probe migration in the peritoneal

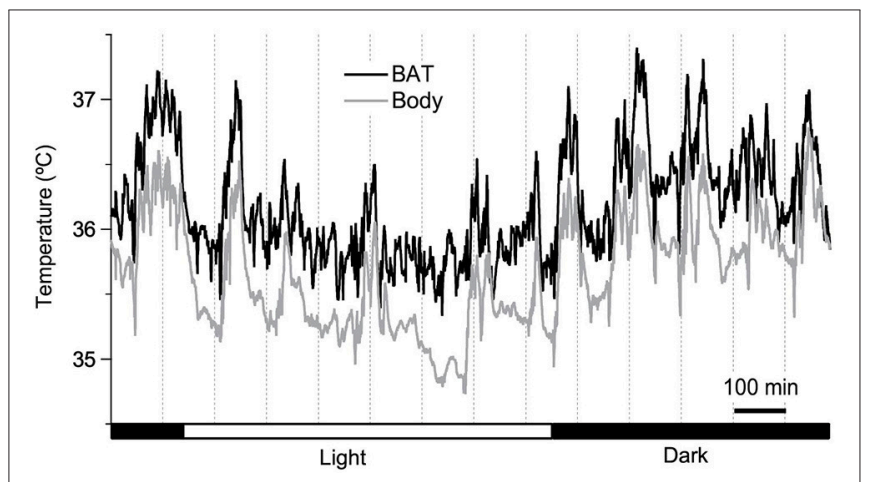

FIGURE 1 | Twenty four-hour brown adipose tissue (BAT) thermometry and abdominal body temperature readings in a freely-moving C57BL/6 mouse maintained at $26^{\circ} \mathrm{C}$. Abdominal temperature was measured using an implanted telemetry transmitter (DSI, ETA-F10). BAT temperature was measured using a thermistor (NTH5G10P, muRata, Kyoto, Japan) implanted between the BAT and the underlying muscle layer in the inter-scapular region near Sulzer's vein, and was connected to a swivel. The resolution of readings was set to $1 \mathrm{~Hz}$. Y. Ootsuka, unpublished data.

cavity, some devices have small loops for suture-anchoring to the abdominal wall. Alternatively, the probe is sometimes left free-floating in the peritoneal cavity, which increases the intraand inter-animal variation in recorded temperature, and is not recommended.

Un-tethered, continuous monitoring of body temperature is more informative compared to single-point probing, e.g., by rectal thermometry, as periodic temperature changes are 


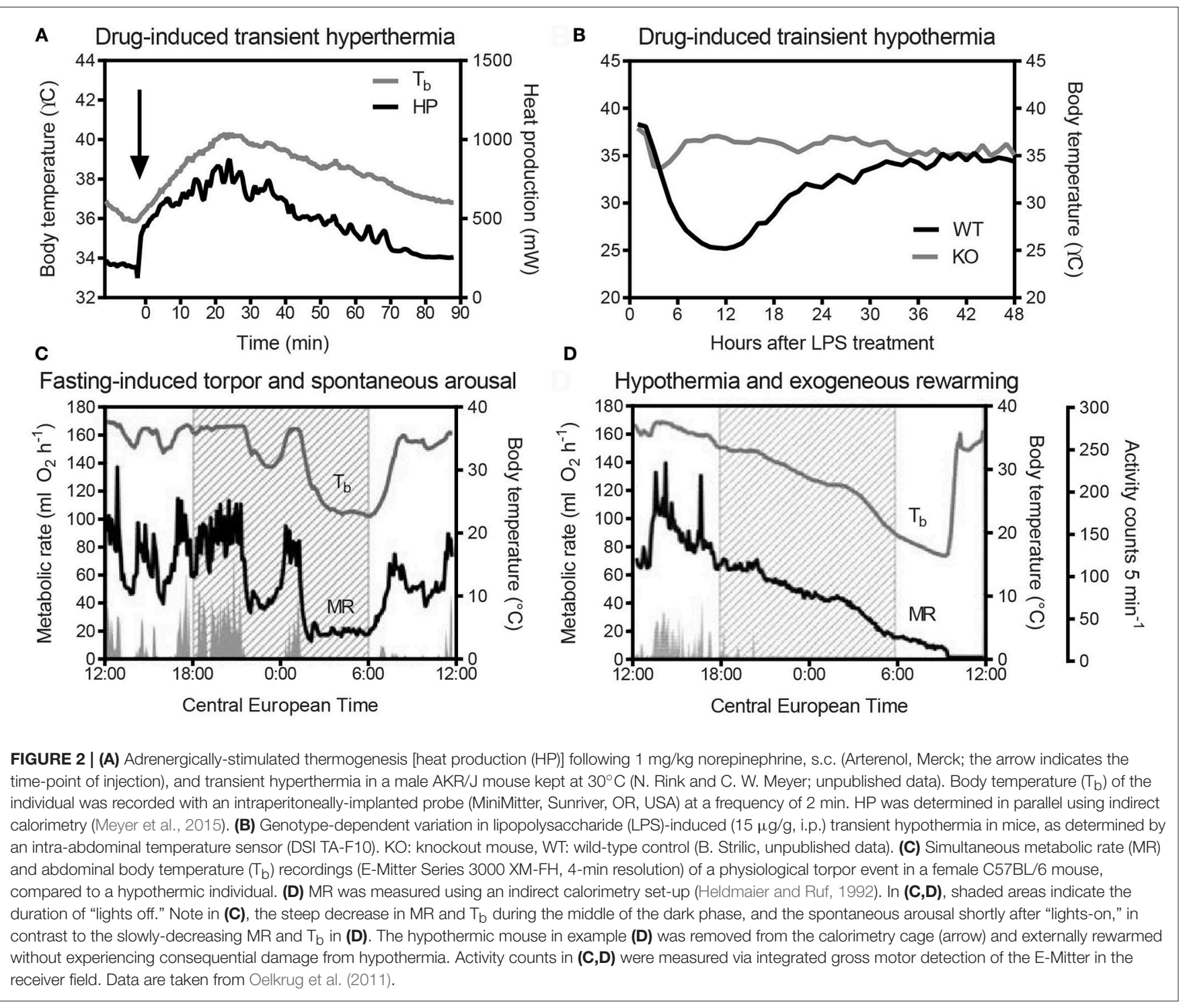

revealed, and data can be obtained in a more physiologicallongitudinal framework. Some examples of valuable readouts derived from metabolic studies involving continuous body temperature measurements in unrestrained mice include circadian temperature patterns (Garami et al., 2011; GerhartHines et al., 2013), ultradian-episodic (“jaggy”) events (Blessing and Ootsuka, 2016; Miyata et al., 2016), genotype- or sex-specific heterothermy (Wither et al., 2012), hyper- or hypothermic responses to pharmacological treatments (Rudaya et al., 2005; Steiner et al., 2007; Garami et al., 2011; Wanner et al., 2012; and Figure 2A), experimental fevers (Rudaya et al., 2005; Steiner et al., 2006), thermoregulatory manifestations of sepsis (Wanner et al., 2012; and Figure 2B), and body temperature patterns of the entrance into, and exit from, torpor (Oelkrug et al., 2011; Solymar et al., 2015; and Figure 2C). An example of an added value of continuous body temperature measurements in the context of cold tolerance is given in Figure 3, which depicts the data from a typical 5-h cold test performed at $4-5^{\circ} \mathrm{C}$ (Meyer et al., 2010). Hourly probing would have correctly identified the cold-tolerant phenotype of the uncoupling protein-1 (UCP1)-KO mouse after pre-acclimation to moderate cold, but this experimental setup would have failed to uncover the absence of periodic fluctuations in abdominal temperature, compared to wild-type. The translational value of continuous data acquisition, as compared to single probing, is also highlighted from studies in female methyl-CpG-binding protein 2 (MeCP2)-deficient mice, which initially demonstrated lower neck temperature determined by transponder. Using telemetry probes, this observation could be extended to reflect disrupted daily rhythmic patterning that mirrors impaired autonomic nervous system function and cardinal phenotypes of clinical Rett syndrome (Ward et al., 2011; Wither et al., 2012).

Some researchers also measure brain temperature in mice and other small rodents by using thermocouples, wired thermistors, or telemetry probes (Deboer et al., 1994; Romanovsky and 

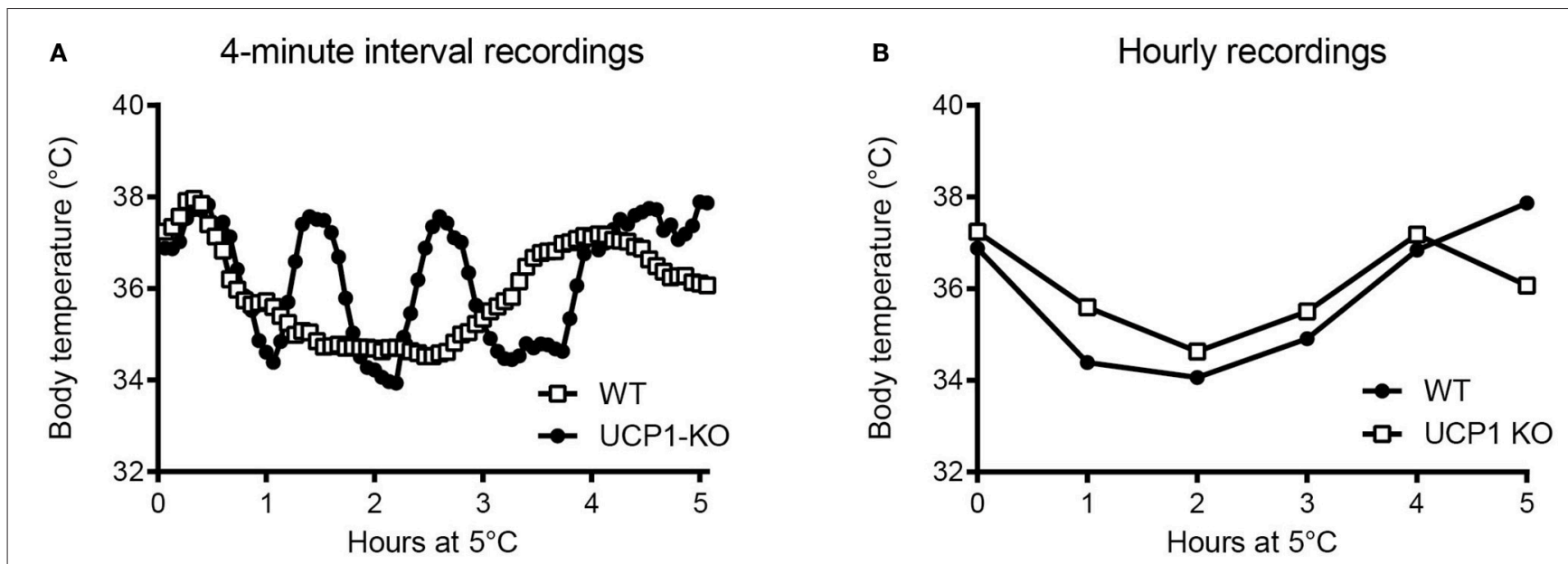

FIGURE 3 | (A) Intra-abdominal body temperature (E-Mitter Series 3000 XM-FH) recorded every 4 min in a wild-type (WT) and an uncoupling protein-1 (UCP1)-knockout (KO) mouse previously acclimated to $18^{\circ} \mathrm{C}$ and acutely exposed to $5^{\circ} \mathrm{C}$. Note the pronounced episodic fluctuations in body temperature of the $\mathrm{WT}$ mouse that are absent in the UCP1-KO mouse. Using the same data sets, we simulated hourly probing (B), demonstrating resolution legacy and the information potentially missed from less-frequent sampling. Data are taken from Meyer et al. (2010).

\section{BOX 5 | IR thermography.}

At temperatures $>0 \mathrm{~K}\left(-273^{\circ} \mathrm{C}\right)$, all object surfaces emit electromagnetic radiation in the infrared range of the electromagnetic spectrum ( $\left.\sim 5-15 \mu \mathrm{m}\right)$. The efficacy by which energy is emitted from surfaces is called emissivity, and the emissivity coefficient (i.e., the radiation of an object in relation to that of a black body) has been determined to be $0.95-0.98$ for biological materials (Cossins and Bowler, 1987). Using this information, infrared energy can be captured by infrared-sensitive cameras and processed into a thermogram, a color-coded image of the surface temperature (Speakman and Ward, 1998).

In order to retrieve reproducible data with IR thermography, important technical aspects need to be considered. For example, the intensity of emitted radiation received from an object is not just affected by its temperature, but also by the angle at which the object is viewed and the distance between the object and the camera. For assessment of living mice, most IR cameras need to be placed vertically above the mouse and within less than $1 \mathrm{~m}$ distance from the animal. Hence, although claiming to be non-invasive, IR measurements of live animals may require a confined space or immobilization (fixation) in order to standardize measurement conditions and the exposed surface area.

Blatteis, 1996; Romanovsky et al., 1996; DeBow and Colbourne, 2003; Conti et al., 2006; Baracchi and Opp, 2008; Steiner et al., 2008; Ootsuka et al., 2009; Baud et al., 2013). In a telemetry probe typically used for this purpose, the XM-FH transmitter, which used to be sold by MiniMitter, the temperature sensor is located at the tip of a stainless steel cannula, which is implanted into the brain, whereas the body of the probe (which contains all the electronics) is affixed to the skull (Steiner et al., 2008).

Brain temperature is measured for different purposes and, therefore, at different locations. In the sleep field, brain temperature is often measured as a cortex temperature and used, for among other purposes, to determine the rapid-eyemovement (REM, or paradoxical) phase of sleep. In REM sleep, the activity of the cortex (and, therefore, the cortex temperature) increases. Hence, in most sleep studies, a brain probe is implanted very superficially-in the cortex, over (just above) the cortex, or even at the dura mater (Deboer et al., 1994; Baracchi and Opp, 2008; Baud et al., 2013). In the thermoregulation field, brain temperature is usually used as an index of deep body temperature or measured in an attempt to determine the temperature at which thermosensitive neurons, that drive autonomic thermoeffector responses, are exposed. For either purpose, the probe is implanted deeperoften into the medial anterior hypothalamus, which in most species is located close to the geometric center of the head
(Romanovsky and Blatteis, 1996; Conti et al., 2006; Baracchi and Opp, 2008; Steiner et al., 2008; Baud et al., 2013). Not surprisingly, therefore, brain temperatures reported in sleep studies (cortex temperature) are often a degree or two lower than brain temperatures reported in thermoregulation studies (hypothalamic temperature).

\section{Infrared (IR) Thermography}

IR thermography, or thermal imaging, decodes the IR radiation emitted from the surface (of an animal) into a color-coded image that can be analyzed in real time or post-recording (Box 5). Of all the methods described in this paper, IR thermography is the least invasive.

In typical applications, IR thermography does not yield deep body temperature, but measures surface (skin) temperature. As evident from individual IR thermograms (Figure 4A), surface heat radiation and, hence, surface temperature are not uniform across the body of the animal, which consists of both non-glabrous (hairy) and glabrous (non-hairy) skin (Romanovsky, 2014). Because of this heterogeneity, radiative temperature data in adult mice are often retrieved not from the entire body surface, but rather from predefined fields of view (FOVs) of a standardized size. Local surface temperature is then calculated as the average temperature across a selected FOV. Alternatively, a series of images is taken and the 
A

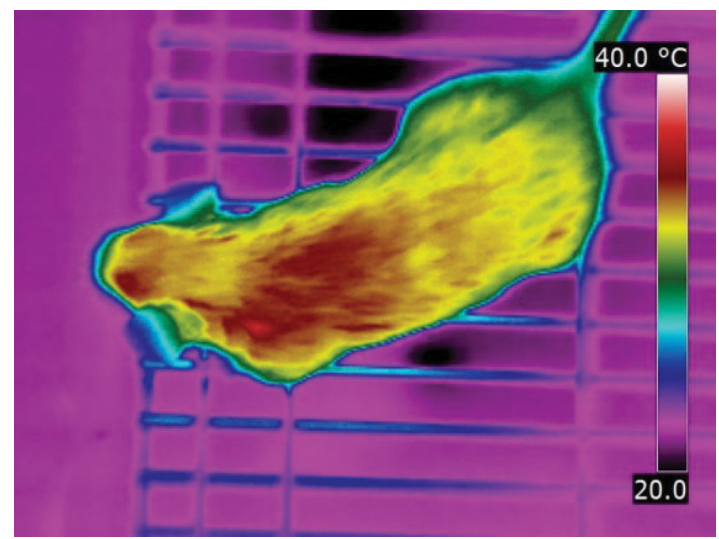

C

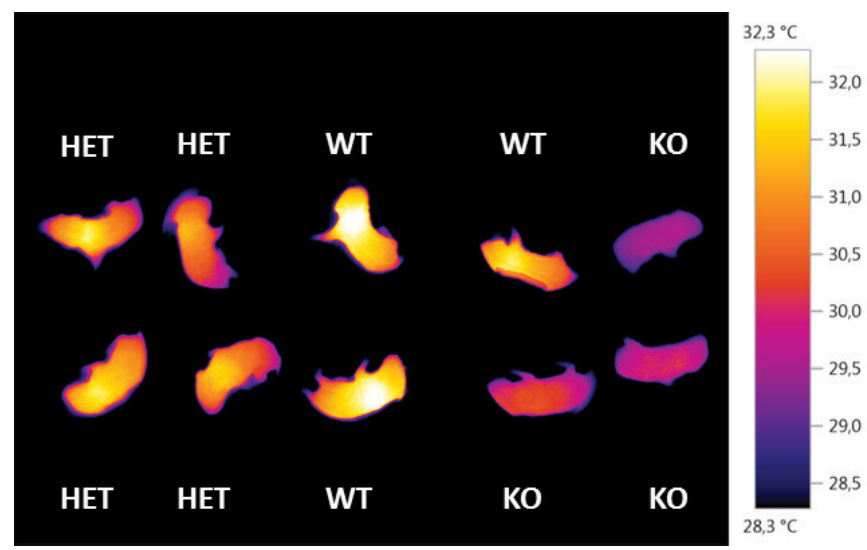

B

Positions 1, 3, and 5: $\operatorname{Trpv1/-}$

Positions 2, 4, and 6: $\bigcirc \operatorname{Trpv1+/+}$

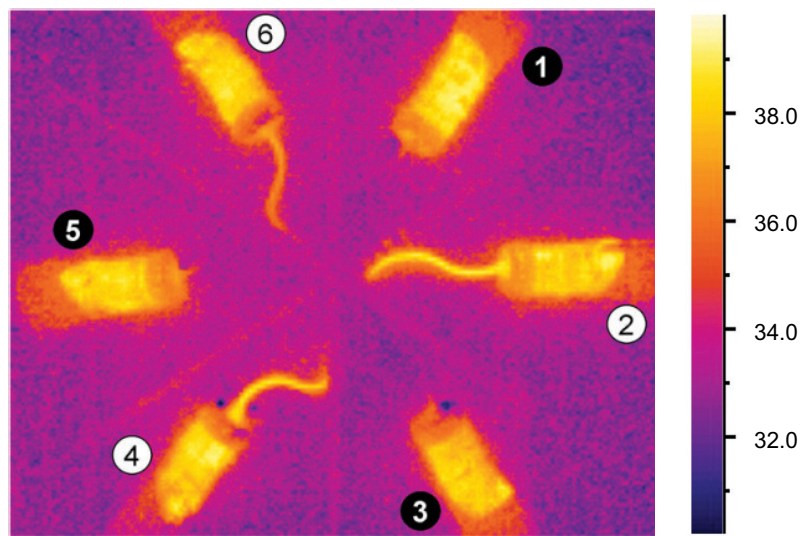

D

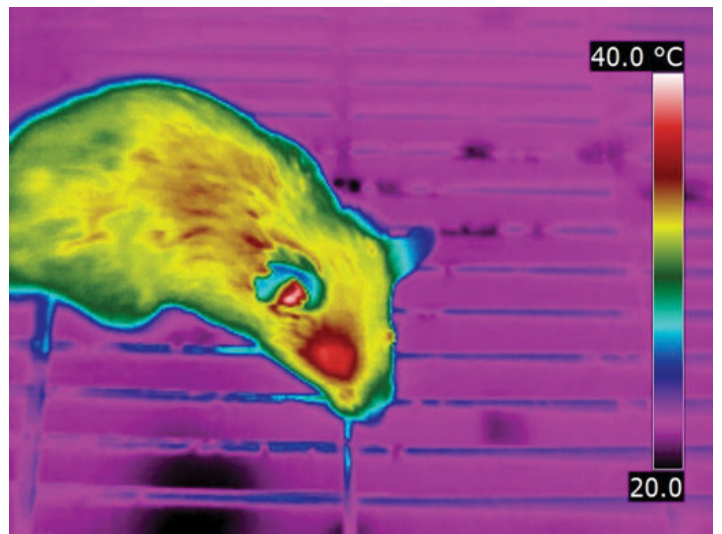

FIGURE 4 | Infrared (IR) thermography in mouse metabolic studies and phenotyping. In each panel, specific color coding of radiant heat is indicated to the right. (A) Dorsal view from an unrestrained, conscious wild-type mouse, captured by IR thermography (T335, FLIR Systems), demonstrating heterogeneity in surface temperatures by color coding. The ambient temperature was set to $22-23^{\circ} \mathrm{C}$. Image kindly provided by R. Oelkrug and J. Mittag, unpublished. (B) Radiant temperature from mouse tails reveals enhanced skin vasoconstriction and altered autonomous vasomotor control in transient receptor potential vanilloid-1 (Trpv1)-knockout (KO) mice compared to wild-type controls (Garami et al., 2011). The IR camera (ThermoVision A20M, FLIR Systems) was positioned above a group of confined, conscious mice inside a climatic chamber at $32^{\circ} \mathrm{C}$. The mice had been previously habituated to the experimental setup by extensive handling.

(C) Whole-body thermography in neonates (p1-p3), highlighting reduced inter-scapular skin-surface temperature in association with genetic knockout of uncoupling protein-1 (UCP-1) and impaired non-shivering thermogenesis. For the measurement, pups were placed in 6-well cell culture plates at $22-23^{\circ} \mathrm{C}$ ambient temperature (Maurer et al., 2015). (D) Lateral view from an unrestrained, conscious wild-type mouse, captured by IR thermography (T335, FLIR Systems) for specific measurement of external acoustic meatus temperature. Ambient temperature was set to $22-23^{\circ} \mathrm{C}$. Image kindly provided by R. Oelkrug and J. Mittag, unpublished.

maximum temperature is determined from the back surface area of the animal (Gachkar et al., 2017). For rather complex technical reasons, some researchers prefer to assess the surface temperature from the frequency distribution of temperature readings across the $\mathrm{FOV}$, e.g., from the warmest $10 \%$ portion (Crane et al., 2014). In general, temperature determined by IR thermography can never overestimate but only underestimate skin temperature.

One of the most robust uses of IR thermography is to assess the thermoeffector role of the glabrous skin of specialized heat-loss organs, such as the tail in mice or rats, the ear in guinea pigs and rabbits, or the hand in humans. Specifically,
IR thermography is used as a measure of vasomotor tone in these organs in order to confirm the presence or absence of vasoconstriction or vasodilation (Rudaya et al., 2005; Wang et al., 2006; Garami et al., 2011; Fischer et al., 2016; Figure 4B). It should be noted, however, that in most circumstances several skin temperature-based indices (e.g., the heat loss index Romanovsky et al., 2002) are better suited for this purpose than the tailskin temperature per se. As an interesting modification suitable for some specific tasks, a semi-quantitative evaluation of the vasomotor tone of the skin covering heat-loss organs can be obtained by painting it with temperature-sensitive paint (Romanovsky et al., 2002). 
Another application of IR thermometry is to use the information from vasomotor tone of heat-loss organs to determine the thermoneutral zone (TNZ; see Romanovsky et al., 2002). The authoritative sources (IUPS Thermal Commission, see Bligh and Johnson, 1973; Mercer and Werner, 2001) define the TNZ as the range of ambient temperatures at which body temperature regulation is achieved only by control of sensible heat loss, i.e., without changes in metabolic heat production or evaporative heat loss. "Sensible," or "Newtonian," heat loss is the total heat loss due to all heat exchange mechanisms, except for evaporation. In practice, the major physiological mechanism of sensible heat loss is cutaneous vasodilation, especially in body parts that serve as heat exchangers with the environment, such as the tail of a mouse. Hence, in a subneutral (cold) environment, the tails of mice exhibit constant maximal vasoconstriction (and are difficult to see in an IR thermogram as they have nearly the same temperature as the environment). In a supraneutral (hot) environment, the tails exhibit constant maximal vasodilation (and may or may not be well-seen on thermograms, depending on the ambient temperature). In a neutral environment (i.e., within the TNZ), the tails constantly change their vasomotor tone from mild vasoconstriction to mild vasodilation, thus become intermittently from almost invisible to highly visible (see Romanovsky et al., 2002, for more detailed information; see Garami et al., 2011, and Figure 4B for examples in mice). For studying thermogenic responses by IR thermography, tight control of the ambient temperature is essential. In such studies, mice should be conscious, as most anesthetics decrease the threshold body temperature for activation of cold defenses - thus, effectively inhibiting thermogenesis (Garami et al., in press).

The utility of IR thermography in assessing the vasomotor control in mice tails is exemplified by the metabolic phenotype of mice expressing a mutant thyroid hormone receptor alpha 1 $(\mathrm{TRa} 1+\mathrm{m})$. In these mice, impaired vasoconstriction of the tail arteries leads to increased heat loss in cold environments and promotes hypothermia, despite elevated brown fat activity and energy expenditure. At first sight, the hypermetabolic phenotype was "paradoxical" (Warner and Mittag, 2014), since the mutation was expected to reduce the affinity of TRa1 to thyroid hormones and, hence, was predicted to lower thermogenesis. Subsequent studies of the thermoregulatory effector organs revealed that $\mathrm{TRa} 1+\mathrm{m}$ mice had a greater need for adaptive thermogenesis, as their vasomotor responses were ineffective at maintaining euthermia. These studies revealed an unexpected role of thyroid hormones in thermoregulation (Sjogren et al., 2007; Warner et al., 2013). Furthermore, these findings demonstrate that hypermetabolism is not necessarily associated with high body temperature.

IR thermography is also used to assess BAT thermogenesis in rodents. For this purpose, most researchers use the difference between radiative temperatures of the inter-scapular backskin (covers the inter-scapular BAT depots) and the lumbar back-skin (reference point) as an index of thermogenesis in the inter-scapular BAT (e.g., Marks et al., 2009; Pazos et al., 2015). We find this approach to be well-grounded. Other researchers capture the absolute values of, or the changes (from basal value) in, the inter-scapular skin temperature for the same purpose
(Gerhart-Hines et al., 2013; Crane et al., 2015). This latter approach is more prone to error, but still seems to work in some cases. For example, the increase in inter-scapular skin temperature observed in wild-type mice $\left(1.7^{\circ} \mathrm{C}\right)$ in response to the selective beta-3 adrenergic agonist CL-316,243 was absent in UCP1-KO mice, corroborating compromised BAT-function (Crane et al., 2014). In contrast, this approach did not allow for the successful quantification of BAT thermogenic capacity following beta-adrenergic stimulation or cold acclimation in a study in voles (Microtus agrestis; Jackson et al., 2001).

Some researchers prefer shaving the skin in trunk FOVs, whilst others do not. Under most conditions, the shaved patches give higher surface temperature readings, as any insulative effect of the pelage is eliminated. In addition, shaving lessens the confounding diffusion and reflection effects of the pelage. Of course, this is not an issue in experiments with nude pups (Figure 4C) or genetically hairless animals (Chen et al., 2013; Schulz et al., 2013; Romanovsky, 2014; Maurer et al., 2015). Whether or not shaving is required depends on the IR signal intensity and the specific goal of measurements. However, we feel that shaving should be avoided whenever possible, as it creates "thermal windows," which may substantially increase heat loss, and thus, potentially change deep body temperature and affects the recruitment of thermoeffectors. Removing the hair also irritates the skin and can lead to inflammation, which can affect local temperatures. If repeated measurements, over a longer period of time, are required - shaving needs to be repeated frequently, as the trunk hair re-grows relatively fast ( $\sim 3$ weeks in adult mice Muller-Rover et al., 2001). This alters conductivity and may subsequently change the cold-stress responsiveness.

IR thermometry also has the potential of assessing deep body temperature, but not by measuring trunk-skin temperature. The recent study by Vogel et al. (2016) proposes measuring radiative temperature of the eyes in mice, as an index of their brain temperature. The external acoustic meatus is another "window to the brain" that can possibly be used for assessing brain temperature of rodents by IR thermography or thermometry (Romanovsky, 2014; Hoefig et al., 2015, 2016, and Figure 4D).

\section{CONCLUDING REMARKS}

Metabolic phenotypes of genetically modified mice can help to establish causality between a specific gene or pathway and energy metabolism in vivo. In this context, animal temperature is often measured to uncover thermoregulatory alterations. Here, we have summarized the main thermometry methods used for the purposes of metabolic phenotyping in mice, and have investigated their utility. It is not only the type of sensor, but also the experimental conditions, probe location and sampling frequency, that determine the biological value of the results, driving successful phenotyping.

For comprehensive phenotyping involving thermometry, the thermal environment of the animals measured must be tightly controlled. Mice are small-sized endotherms with relatively high basal metabolic costs, owing to their unfavorable surface area to volume ratio (Kleiber, 1961). Mouse pelage has relatively poor insulative capacities, making this species sensitive 
to cold and specifically reliant on creating and exploiting thermally advantageous microenvironments for cost-efficient body temperature regulation (Hart, 1971). Any metabolic study in mice, therefore, not only requires considerations of room temperature (gradients and variation) in the animal facility/experimental location, but also of the "operative ambient temperature" created by the animals inside the cage (Gordon et al., 1998). Factors known to affect individual metabolic costs, at otherwise constant room air temperature, are the type and amount of bedding material, nest material, and the opportunity to huddle with cagemates (Himms-Hagen and Villemure, 1992; Gordon et al., 1998; Gordon, 2004; David et al., 2013; Maher et al., 2015). Hence, control of any of these parameters potentially reduces variance in output values. Following the same reasoning, researchers should also keep in mind that any intervention or incident that disrupts the integrity of the skin/fur (e.g., shaving, surgery, alopecia) may cause specific thermoregulatory adjustments potentially contributing to extra variation in metabolic costs.

In order to provide a more complete thermoregulatory portrait of a certain genotype, it is essential that thermometry not be limited to measurements of body temperature under standard housing conditions. Rather, temperature readings should be obtained and compared at thermoneutral vs. subthermoneutral (cold) and supra-neutral (warm) conditions - aiming to reveal specific deficiencies in cold and heat defenses. For the same purpose, we advocate combining measurements of core body temperature with tail thermography and back thermography (Gachkar et al., 2017). In order to reveal thermoregulatory phenotypes associated with behavioral thermoregulation, temperature readings could be combined with, for example, food restriction challenges (Haemmerle et al., 2006; Meyer et al., 2010), behavioral tasks, e.g., temperature preference chambers, thermal gradients (Gordon et al., 1998;
Bautista et al., 2007), or operant conditioning for thermal reward (Baldwin, 1968; Carlisle and Dubuc, 1982).

It is advantageous to conduct high-resolution core body temperature measurements in conjunction with measurements of metabolic rate, for the assessment for heat production rates at tightly controlled ambient temperatures. This experimental scheme not only determines the energy expenditure and associated body temperature variations, but also allows for the assessment of thermal conductance of the animals (Box 6)-a quantitative measure of the rate of heat exchange between the animal's body and the environment (McNab, 1980). In the example shown in Figure 5, thermal conductance is compared in the context of cold tolerance in UCP1-KO mice. Conductance is consistently lower in cold-acclimated UCP1-KO mice, which supports the conclusion that cold acclimation in the absence of functional BAT involves specific heat-conserving mechanisms, including improved tail vasoconstriction (Wang et al., 2006).

In terms of animal welfare, hyper- or hypothermic thresholds are to be established and applied carefully, as periodic deviations from "normal" temperature ranges are context-, time- and strain-dependent, and may not unequivocally indicate an acute life-threatening condition. For example, during torpor, a physiological state of metabolic depression (Jastroch et al., 2016), the abdominal body temperature of a mouse may transiently reach values that are only half a degree higher than the ambient temperature. Murine torpor commonly occurs during the early morning hours and can, in principle, be diagnosed by rectal probing. Following handling, acoustic, haptic or mechanical stimulation, a healthy mouse "alarm-arouses" and regains what is often referred to as normal metabolism and normothermy within 1-2 $\mathrm{h}$, depending on the degree of metabolic depression and the ambient temperature. Of note, the classification of normothermy vs. torpor is often based on metrics of heterothermy, e.g., the amplitude of daily body temperature fluctuations (see Levesque

\section{BOX 6 | Thermal conductance.}

Metabolic phenotypes involving alterations in body temperature often depend on changes in thermogenesis (heat production), but they also reflect altered heat loss characteristics. Thermal conductance $[C]$ describes the rate of heat production necessary to compensate for heat loss, i.e., the difference in temperature between the body and its surroundings (ambient temperature, $T_{\mathrm{a}}$ ). Mathematically, $C$ is obtained from the slope of the linear increase in (dry) heat loss (excluding evaporation) with decreasing ambient temperature $\left(T_{a}\right)$ at temperatures cooler than thermoneutrality (Equation 1). For comparative purposes, thermal conductance should be indicated as a positive number, indicating that heat exchange is directed from the warmer to the cooler environment and not vice versa (McNab, 1980).

$$
\text { Equation 1: } \begin{aligned}
\mathrm{C} & =\mathrm{HP}^{*}\left(\mathrm{~T}_{\mathrm{b}}-\mathrm{T}_{\mathrm{a}}\right)^{-1} \\
\mathrm{C} & =\text { thermal conductance }\left(\mathrm{Watts}^{\circ} \mathrm{C}^{-1}\right) \\
\mathrm{HP} & =\text { heat production }(\text { Watts, } \mathrm{W}) \\
\mathrm{T}_{\mathrm{b}} & =\text { body temperature }\left({ }^{\circ} \mathrm{C}\right) \\
\mathrm{T}_{\mathrm{a}} & =\text { ambient }\left(\text { air) temperature }\left({ }^{\circ} \mathrm{C}\right)\right.
\end{aligned}
$$

Figure 5A depicts an example of this type of analysis for cold-acclimated uncoupling-protein 1 (UCP1)-knockout (KO) mice. HP was determined using indirect calorimetry. When only HP associated with resting conditions is considered, the HP- $\mathrm{T}_{\mathrm{a}}$ regression extrapolates to predicted resting body temperature ("theoretical body temperature") at zero $\mathrm{HP}$, and the slope of the $\mathrm{T}_{\mathrm{a}}-\mathrm{HP}$ regression elucidates minimal conductance (i.e., the minimal rate of heat production required to maintain the largest possible normothermic $\mathrm{T}_{\mathrm{b}}-\mathrm{T}_{\mathrm{a}}$ gradient; $\left.\mathrm{McNab}, 1980\right)$. In the example shown in Figure 5A, the predicted thermal conductance (slope) is lower in UCP1-KO mice (at $p<0.08$ ), and the expected core $\mathrm{T}_{\mathrm{b}}$ is similar between genotypes, with a trend toward higher values in KO mice. Biologically, this indicates that UCP1-KO mice are more efficient at conserving heat.

Alternatively, $\mathrm{HP}, \mathrm{T}_{\mathrm{a}}$, and core $\mathrm{T}_{\mathrm{b}}$ are measured jointly and $\mathrm{C}$ is obtained using Equation (1). Re-analysing the data and including the corresponding abdominal $\mathrm{T}_{\mathrm{b}} \mathrm{S}$ measured in the same individuals confirmed that average thermal conductance in moderate cold was lower in UCP1-KO mice, (Figure 5B). 

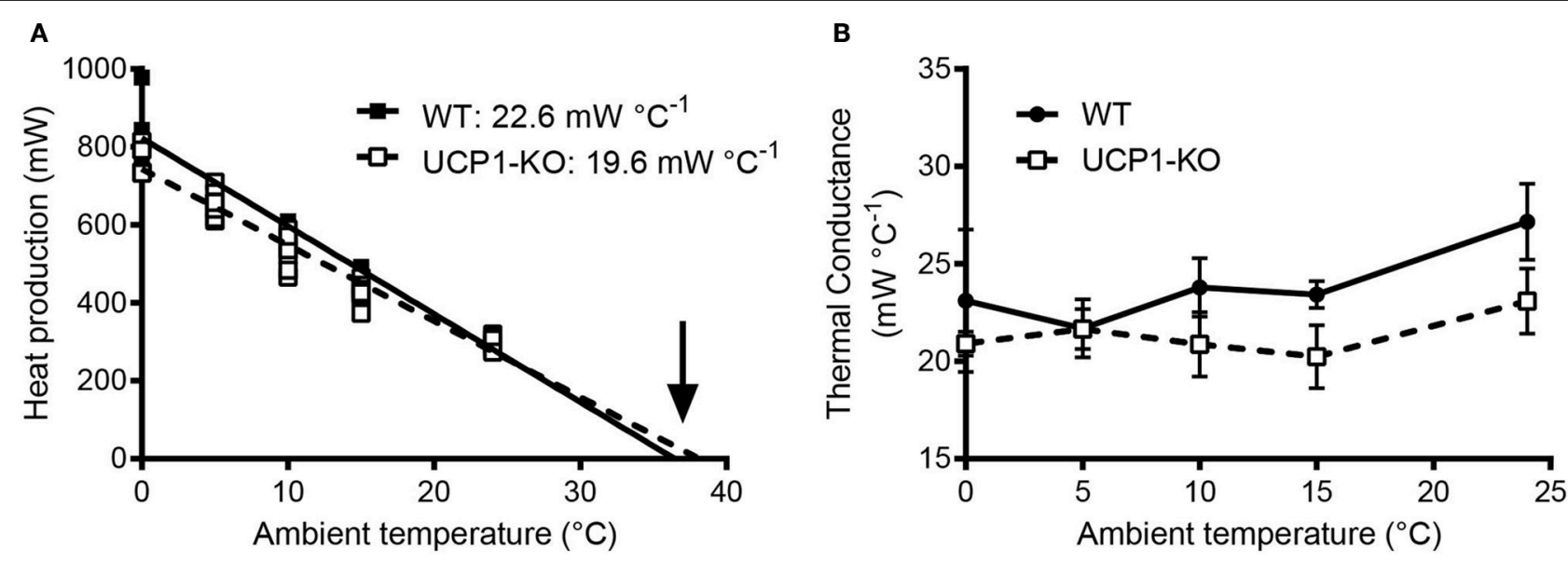

FIGURE 5 | (A) Assessment of thermal conductance using resting heat production rates collected in wild-type and uncoupling-protein-1 (UCP1-KO)-deficient littermates at different ambient temperatures ("Scholander-Irving plot"; Scholander et al., 1950). Average slopes corresponding to predicted minimal thermal conductance (expressed as positive values) are indicated for each genotype ( $p=0.08, t$-test). The arrow highlights the $\mathrm{x}$-axis intersection points corresponding to the predicted average body temperature during resting conditions (not different between genotypes; $p=0.44$, $t$-test). (B) Calculated thermal conductance (see Box $\mathbf{6}$ )

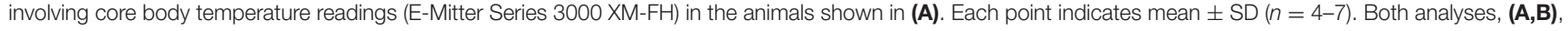
are supporting lower thermal conductance and thus an altered thermoregulatory strategy involving improved heat conservation in UCP1-KO mice. Data are taken from Meyer et al. (2010).

et al., 2016, for further reading and current discussion). If a torpid mouse is left undisturbed, spontaneous arousal usually takes place by late morning to midday, but the specific onset of this process and the duration of torpor can be highly variable among strains and individuals (Dikic et al., 2008). In contrast, animals with severe energetic depletion or some metabolic deficiencies are often unable to rewarm themselves endogenously (Haemmerle et al., 2006; Oelkrug et al., 2011). In this case, 1-2 h of passive rewarming (e.g., through infrared heaters) and food and water provision are warranted (Figure 2D). Torpor frequency and associated temperature changes can be considered a metabolic phenotype and, as such, merit exploration (Jethwa et al., 2008; Swoap, 2008; Willershäuser et al., 2012).

In naive mice, a stress-induced body temperature rise can be initiated by opening the cage or even by entering the animal room. In addition, when mice are picked one-by-one from a cage, the level of distress builds up in the remaining mice kept in this cage, and the measured body temperature increases drastically from the first to the last mouse taken from the cage (Zethof et al., 1994). In this case, and in many other cases, part of the increase in body temperature can be explained by motor activity, which is directly thermogenic. Indeed, changes in the body temperature of mice follow, with some delay, changes in their motor activity (Lateef et al., 2014). In contrast, data in rats and humans suggest that rises in core temperature precede the onset of activity (Refinetti and Menaker, 1992; Decoursey et al., 1998; Ootsuka et al., 2009), as is noted to occur during ultradian cycles. While the discussion of the presence and significance of ultradian rhythms in thermogenesis is beyond the scope of this review, the technical sensitivity assessing ultradian fluctuations and temporal associations in body temperature with other physiological parameters is critically dependent on the sampling interval. In this context, we and others (Blessing and Ootsuka, 2016) recommend examination of the individual records be routinely performed before any results are averaged.

Taken together, thermometry significantly expands the metabolic phenotyping toolbox, because the interplay between heat loss and heat production can be addressed (e.g., Kaiyala et al., 2015; Abreu-Vieira et al., 2015; Fischer et al., 2016, 2017). Multiparametric measurements involving thermometry increase the probability of revealing distinct metabolic and thermoregulatory phenotypes.

\section{ETHICS STATEMENT}

This work does not contain any animal data that was specifically collected for the purpose of publication in this manuscript. Animal data presented refer to approved experiments published elsewhere.

\section{AUTHOR CONTRIBUTIONS}

All authors have made substantial contributions to the conception or design of the work, which includes drafting the work, and revising it critically for important intellectual content.

\section{ACKNOWLEDGMENTS}

CWM would like to thank Iain Patten for support with the initial drafting of this work. All authors thank Anna Antipov for language editing. 


\section{REFERENCES}

Abreu-Vieira, G., Xiao, C., Gavrilova, O., and Reitman, M. L. (2015). Integration of body temperature into the analysis of energy expenditure in the mouse. Mol. Metab. 4, 461-470. doi: 10.1016/j.molmet.2015.03.001

Almeida, M. C., Hew-Butler, T., Soriano, R. N., Rao, S., Wang, W., Wang, J., et al. (2012). Pharmacological blockade of the cold receptor TRPM8 attenuates autonomic and behavioral cold defenses and decreases deep body temperature. J. Neurosci. 32, 2086-2099. doi: 10.1523/JNEUROSCI.5606-11.2012

Almeida, M. C., Steiner, A. A., Branco, L. G., and Romanovsky, A. A. (2006). Coldseeking behavior as a thermoregulatory strategy in systemic inflammation. Eur. J. Neurosci. 23, 3359-3367. doi: 10.1111/j.1460-9568.2006.04854.x

Bal, N. C., Maurya, S. K., Sopariwala, D. H., Sahoo, S. K., Gupta, S. C., Shaikh, S. A., et al. (2012). Sarcolipin is a newly identified regulator of musclebased thermogenesis in mammals. Nat. Med. 18, 1575-1579. doi: 10.1038/ nm. 2897

Baldwin, B. A. (1968). Behavioural thermoregulation in mice. Physiol. Behav. 3, 401-407. doi: 10.1016/0031-9384(68)90069-3

Baracchi, F., and Opp, M. R. (2008). Sleep-wake behavior and responses to sleep deprivation of mice lacking both interleukin-1 beta receptor 1 and tumor necrosis factor-alpha receptor 1. Brain Behav. Immun. 22, 982-993. doi: 10.1016/j.bbi.2008.02.001

Baud, M. O., Magistretti, P. J., and Petit, J. M. (2013). Sustained sleep fragmentation affects brain temperature, food intake and glucose tolerance in mice. J. Sleep Res. 22, 3-12. doi: 10.1111/j.1365-2869.2012.01029.x

Bautista, D. M., Siemens, J., Glazer, J. M., Tsuruda, P. R., Basbaum, A. I., Stucky, C. L., et al. (2007). The menthol receptor TRPM8 is the principal detector of environmental cold. Nature 448, 204-208. doi: 10.1038/nature05910

Blessing, W., and Ootsuka, Y. (2016). Timing of activities of daily life is jaggy: how episodic ultradian changes in body and brain temperature are integrated into this process. Temperature (Austin) 3, 371-383. doi: 10.1080/23328940.2016.1177159

Bligh, J., and Johnson, K. G. (1973). Glossary of terms for thermal physiology. J. Appl. Physiol. 36, 941-961.

Carlisle, H. J., and Dubuc, P. U. (1982). Unchanged thermoregulatory set-point in the obese mouse. Nature 297, 678-679. doi: 10.1038/297678a0

Chen, Y., Siegel, F., Kipschull, S., Haas, B., Frohlich, H., Meister, G., et al. (2013). miR-155 regulates differentiation of brown and beige adipocytes via a bistable circuit. Nat. Commun. 4:1769. doi: 10.1038/ncomms 2742

Clement, J. G., Mills, P., and Brockway, B. (1989). "Use of telemetry to record body temperature and activity in mice." J. Pharmacol. Methods 21, 129-140. doi: 10.1016/0160-5402(89)90031-4

Conti, B., Sanchez-Alavez, M., Winsky-Sommerer, R., Morale, M. C., Lucero, J., Brownell, S., et al. (2006). Transgenic mice with a reduced core body temperature have an increased life span. Science 314, 825-828. doi: 10.1126/science.1132191

Cossins, A. R., and Bowler, K. (1987). Temperature Biology of Animals. London; New York, NY: Chapman and Hall.

Crane, J. D., Mottillo, E. P., Farncombe, T. H., Morrison, K. M., and Steinberg, G. R. (2014). A standardized infrared imaging technique that specifically detects UCP1-mediated thermogenesis in vivo. Mol. Metab. 3, 490-494. doi: 10.1016/j.molmet.2014.04.007

Crane, J. D., Palanivel, R., Mottillo, E. P., Bujak, A. L., Wang, H., Ford, R. J., et al. (2015). Inhibiting peripheral serotonin synthesis reduces obesity and metabolic dysfunction by promoting brown adipose tissue thermogenesis. Nat. Med. 21, 166-172. doi: $10.1038 / \mathrm{nm} .3766$

David, J. M., Knowles, S., Lamkin, D. M., and Stout, D. B. (2013). Individually ventilated cages impose cold stress on laboratory mice: a source of systemic experimental variability. J. Am. Assoc. Lab. Anim. Sci. 52, 738-744.

Deboer, T., Franken, P., and Tobler, I. (1994). Sleep and cortical temperature in the Djungarian hamster under baseline conditions and after sleep deprivation. J. Com. Physiol. A 174, 145-155. doi: 10.1007/bf00193782

DeBow, S., and Colbourne, F. (2003). Brain temperature measurement and regulation in awake and freely moving rodents. Methods 30, 167-171. doi: 10.1016/s1046-2023(03)00080-x

Decoursey, P. J., Pius, S., Sandlin, C., Wethey, D., and Schull, J. (1998). Relationship of circadian temperature and activity rhythms in two rodent species. Physiol. Behav. 65, 457-463. doi: 10.1016/S0031-9384(98)00187-5
Dikic, D., Heldmaier, G., and Meyer, C. W. (2008). "Induced torpor in different strains of laboratory mice," in Hypometabolism in Animals: Torpor, Hibernation and Cryobiology, eds B. G. Lovegrove and A. E. McKechnie (Pietermaritzburg: University of KwaZulu-Natal), 223-230.

Donhoffer, S. (1980). Homeothermia of the Brain: Cerebral Blood Flow, Metabolic Rate, and Brain Temperature in the Cold: the Possible Role of Neuroglia. Budapest, Akadémiai Kiadó.

Fischer, A. W., Hoefig, C. S., Abreu-Vieira, G., de Jong, J. M., Petrovic, N., Mittag, J., et al. (2016). Leptin raises defended body temperature without activating thermogenesis. Cell Rep. 14, 621-1631. doi: 10.1016/j.celrep.2016.01.041

Fischer, K., Ruiz, H. H., Jhun, K., Finan, B., Oberlin, D. J., van der Heide, V., et al. (2017). Alternatively activated macrophages do not synthesize catecholamines or contribute to adipose tissue adaptive thermogenesis. Nat. Med. 23, 623-630. doi: $10.1038 / \mathrm{nm} .4316$

Gachkar, S., Oelkrug, R., Martinez-Sanchez, N., Rial-Pensado, E., Warner, A., Hoefig, C. S., et al. (2017). 3-Iodothyronamine induces tail vasodilation through central action in male mice. Endocrinology 158, 1977-1984. doi: 10.1210/en.2016-1951

Garami, A., Ibrahim, M., Gilbrait, K., Khanna, R., Pakai, E., Miko, A., et al. (in press). TRPV1 antagonists prevent anesthesia-induced hypothermia and decrease post-incisional opioid dose requirements in rodents. Anesthesiology.

Garami, A., Pakai, E., Oliveira, D. L., Steiner, A. A., Wanner, S. P., Almeida, M. C., et al. (2011). Thermoregulatory phenotype of the Trpvl knockout mouse: thermoeffector dysbalance with hyperkinesis. J. Neurosci. 31, 1721-1733. doi: 10.1523/JNEUROSCI.4671-10.2011

Gerhart-Hines, Z., Feng, D., Emmett, M. J., Everett, L. J., Loro, E., Briggs, E. R., et al. (2013). The nuclear receptor Rev-erbalpha controls circadian thermogenic plasticity. Nature 503, 410-413. doi: 10.1038/nature12642

Gordon, C. J. (1993). Temperature Regulation in Laboratory Rodents. Cambridge: Cambridge University Press.

Gordon, C. J. (2004). Effect of cage bedding on temperature regulation and metabolism of group-housed female mice. Comp. Med. 54, 63-68.

Gordon, C. J., Becker, P., and Ali, J. S. (1998). Behavioral thermoregulatory responses of single- and group-housed mice. Physiol. Behav. 65, 255-262. doi: 10.1016/S0031-9384(98)00148-6

Haemmerle, G., Lass, A., Zimmermann, R., Gorkiewicz, G., Meyer, C., Rozman, J., et al. (2006). Defective lipolysis and altered energy metabolism in mice lacking adipose triglyceride lipase. Science 312, 734-737. doi: 10.1126/science.1123965

Hart, J. S. (1971). "Rodents," in Comparative Physiology of Thermoregulation, Vol. 2, eds G. C. Whittow (New York, NY; London: Academic Press), 1-149.

Hashimoto, K., Suemaru, S., Takao, T., Sugawara, M., Makino, S., and Ota, Z. (1988). Corticotropin-releasing hormone and pituitaryadrenocortical responses in chronically stressed rats. Regul. Pept. 23, 17-126. doi: 10.1016/0167-0115(88)90019-5

Heldmaier, G., and Ruf, T. (1992). Body temperature and metabolic rate during natural hypothermia in endotherms. J. Comp. Physiol. B. Biochem. Syst. Environ. Physiol. 162, 696-706. doi: 10.1007/BF00301619

Himms-Hagen, J., and Villemure, C. (1992). Number of mice per cage influences uncoupling protein content of brown adipose tissue. Proc. Soc. Exp. Biol. Med. 200, 502-506. doi: 10.3181/00379727-200-43461

Hoefig, C. S., Harder, L., Oelkrug, R., Meusel, M., Vennstrom, B., Brabant, G., et al. (2016). Thermoregulatory and cardiovascular consequences of a transient Thyrotoxicosis and recovery in male mice. Endocrinology 157, 2957-2967. doi: 10.1210/en.2016-1095

Hoefig, C. S., Jacobi, S. F., Warner, A., Harder, L., Schanze, N., Vennstrom, B., et al. (2015). 3-Iodothyroacetic acid lacks thermoregulatory and cardiovascular effects in vivo. Br. J. Pharmacol. 172, 3426-3433. doi: 10.1111/bph.13131

Jackson, D. M., Hambly, C., Trayhurn, P., and Speakman, J. R. (2001). Can non-shivering thermogenesis in brown adipose tissue following NA injection be quantified by changes in overlying surface temperatures using infrared thermography? J. Therm. Biol. 26, 85-93. doi: 10.1016/S0306-4565(00) 00023-1

Jastroch, M., Giroud, S., Barrett, P., Geiser, F., Heldmaier, G., and Herwig, A. (2016). Seasonal control of mammalian energy balance: recent advances in the understanding of daily torpor and hibernation. J. Neuroendocrinol. 28. doi: $10.1111 /$ jne. 12437

Jethwa, P. H., I’Anson, H., Warner, A., Prosser, H. M., Hastings, M. H., Maywood, E. S., et al. (2008). Loss of prokineticin receptor 2 signaling predisposes mice 
to torpor. Am. J. Physiol. Regul. Integr. Comp. Physiol. 294, R1968-R1979. doi: 10.1152/ajpregu.00778.2007

Kaiyala, K. J., Ogimoto, K., Nelson, J. T., Schwartz, M. W., and Morton, G. J. (2015). Leptin signaling is required for adaptive changes in food intake, but not energy expenditure, in response to different thermal conditions. PLoS ONE 10:e0119391. doi: 10.1371/journal.pone.0119391

Kleiber, M. (1961). The Fire of Life. New York, NY; London: John Wiley and Sons Inc.

Lateef, D. M., Abreu-Vieira, G., Xiao, C., and Reitman, M. L. (2014). Regulation of body temperature and brown adipose tissue thermogenesis by bombesin receptor subtype-3. Am. J. Physiol. Endocrinol. Metab. 306, E681-E687. doi: 10.1152/ajpendo.00615.2013

Levesque, D., Nowack, J., and Stawski, C. (2016). Modelling mammalian energetics: the heterothermy problem. Clim. Change Respon. 3:7. doi: 10.1186/s40665-016-0022-3

Maher, R. L., Barbash, S. M., Lynch, D. V., and Swoap, S. J. (2015). Group housing and nest building only slightly ameliorate the cold stress of typical housing in in female C57BL/6J mice. Am. J. Physiol. Regul. Integr. Comp. Physiol. 308, R1070-R1079. doi: 10.1152/ajpregu.00407.2014

Marks, A., Vianna, D. M., and Carrive, P. (2009). Nonshivering thermogenesis without interscapular brown adipose tissue involvement during conditioned fear in the rat. Am. J. Physiol. Regul. Integr. Comp. Physiol. 296, R1239-R1247. doi: 10.1152/ajpregu.90723.2008

Maurer, S. F., Fromme, T., Grossman, L. I., Huttemann, M., and Klingenspor, M. (2015). The brown and brite adipocyte marker Cox7al is not required for non-shivering thermogenesis in mice. Sci. Rep. 5:17704. doi: 10.1038/srep17704

McNab, B. K. (1980). On estimating thermal conductance in endotherms. Physiol. Zool. 53, 145-156. doi: 10.1086/physzool.53.2.30152577

Melia, K. R., Ryabinin, A. E., Schroeder, R., Bloom, F. E., and Wilson, M. C. (1994). Induction and habituation of immediate early gene expression in rat brain by acute and repeated restraint stress. J. Neurosci. 14, 5929-5938.

Mercer, J. G., and Werner, J. (2001). Glossary of terms for thermal physiology. Jpn. J. Physiol. 51, 245-280.

Meyer, C. W., Reitmeir, P., and Tschop, M. H. (2015). Exploration of Energy Metabolism in the Mouse Using Indirect Calorimetry: measurement of daily energy expenditure (DEE) and basal metabolic rate (BMR). Curr. Protoc. Mouse Biol. 5, 205-222. doi: 10.1002/9780470942390. mo140216

Meyer, C. W., Willershauser, M., Jastroch, M., Rourke, B. C., Fromme, T., Oelkrug, R., et al. (2010). Adaptive thermogenesis and thermal conductance in wildtype and UCP1-KO mice. Am. J. Physiol. Regul. Integr. Comp. Physiol. 299, R1396-R1406. doi: 10.1152/ajpregu.00021.2009

Miyata, K., Kuwaki, T., and Ootsuka, Y. (2016). The integrated ultradian organization of behavior and physiology in mice and the contribution of orexin to the ultradian patterning. Neuroscience 334, 119-133. doi: 10.1016/j.neuroscience.2016.07.041

Mohammed, M., Ootsuka, Y., Yanagisawa, M., and Blessing, W. (2014). Reduced brown adipose tissue thermogenesis during environmental interactions in transgenic rats with ataxin-3-mediated ablation of hypothalamic orexin neurons. Am. J. Physiol. Regul. Integr. Comp. Physiol. 307, R978-R989. doi: 10.1152/ajpregu.00260.2014

Moir, L., Bentley, L., and Cox, R. D. (2016). Comprehensive energy balance measurements in mice. Curr. Protoc. Mouse Biol. 6, 211-222. doi: $10.1002 /$ cpmo.13

Muller, T. D., Lee, S. J., Jastroch, M., Kabra, D., Stemmer, K., Aichler, M., et al. (2013). p62 links beta-adrenergic input to mitochondrial function and thermogenesis. J. Clin. Invest. 123, 469-478. doi: 10.1172/JCI64209

Muller-Rover, S., Handjiski, B., van der Veen, C., Eichmuller, S., Foitzik, K., McKay, I. A., et al. (2001). A comprehensive guide for the accurate classification of murine hair follicles in distinct hair cycle stages. J. Invest. Dermatol. 117, 3-15. doi: 10.1046/j.0022-202x.2001.01377.x

Oelkrug, R., Heldmaier, G., and Meyer, C. W. (2011). Torpor patterns, arousal rates, and temporal organization of torpor entry in wildtype and UCP1ablated mice. J. Comp. Physiol. B. Biochem. Syst. Environ. Physiol. 181, 137-145. doi: 10.1007/s00360-010-0503-9

Ootsuka, Y., de Menezes, R. C., Zaretsky, D. V., Alimoradian, A., Hunt, J., Stefanidis, A., et al. (2009). Brown adipose tissue thermogenesis heats brain and body as part of the brain-coordinated ultradian basic restactivity cycle. Neuroscience 164, 849-861. doi: 10.1016/j.neuroscience.2009. 08.013

Ootsuka, Y., Heidbreder, C. A., Hagan, J. J., and Blessing, W. W. (2007). Dopamine D2 receptor stimulation inhibits cold-initiated thermogenesis in brown adipose tissue in conscious rats. Neuroscience 147, 127-135. doi: 10.1016/j.neuroscience.2007.04.015

Pazos, P., Lima, L., Tovar, S., Gonzalez-Touceda, D., Dieguez, C., and Garcia, M. C. (2015). Divergent responses to thermogenic stimuli in BAT and subcutaneous adipose tissue from interleukin 18 and interleukin 18 receptor 1-deficient mice. Sci. Rep. 5:17977. doi: 10.1038/srep17977

Refinetti, R., and Menaker, M. (1992). The circadian rhythm of body temperature. Physiol. Behav. 51, 613-637. doi: 10.1016/0031-9384(92)90188-8

Romanovsky, A. (2014). Skin temperature: its role in thermoregulation. Acta Physiol. 210, 498-507. doi: 10.1111/apha.12231

Romanovsky, A. A., and Blatteis, C. M. (1996). Heat stroke: opioid-mediated mechanisms. J. Appl. Physiol. 81, 2565-2570.

Romanovsky, A. A., Ivanov, A. I., and Shimansky, Y. P. (2002). Selected contribution: ambient temperature for experiments in rats: a new method for determining the zone of thermal neutrality. J. Appl. Physiol. 92, 2667-2679. doi: 10.1152/japplphysiol.01173.2001

Romanovsky, A. A., Kulchitsky, V. A., Akulich, N. V., Koulchitsky, S. V., Simons, C. T., Sessler, D. I., et al. (1996). First and second phases of biphasic fever: two sequential stages of the sickness syndrome? Am. J. Physiol. 271(1 Pt 2), R244-R253.

Romanovsky, A. A., Simons, C. T., and Kulchitsky, V. A. (1998). Biphasic fevers often consist of more than two phases. Am. J. Physiol. 275(1 Pt 2), R323-R331.

Romanovsky, A. A., Simons, C. T., Szekely, M., and Kulchitsky, V. A. (1997). The vagus nerve in the thermoregulatory response to systemic inflammation. Am. J. Physiol. 273(1 Pt 2), R407-R413.

Rozman, J., Klingenspor, M., and Hrabe de Angelis, M. (2014). A review of standardized metabolic phenotyping of animal models. Mamm. Genome 25, 497-507. doi: 10.1007/s00335-014-9532-0

Rudaya, A. Y., Steiner, A. A., Robbins, J. R., Dragic, A. S., and Romanovsky, A. A. (2005). Thermoregulatory responses to lipopolysaccharide in the mouse: dependence on the dose and ambient temperature. Am. J. Physiol. Regul. Integr. Comp. Physiol. 289, R1244-R1252. doi: 10.1152/ajpregu.00370.2005

Scholander, P. F., Hock, R., Walters, V., and Irving, L. (1950). Adaptation to cold in arctic and tropical mammals and birds in relation to body temperature insulation, and basal metabolic rate. Biol. Bull. 99, 259-271. doi: $10.2307 / 1538742$

Schulz, T. J., Huang, P., Huang, T. L., Xue, R., McDougall, L. E., Townsend, K. L., et al. (2013). Brown-fat paucity due to impaired BMP signalling induces compensatory browning of white fat. Nature 495, 379-383. doi: 10.1038/nature11943

Sjogren, M., Alkemade, A., Mittag, J., Nordstrom, K., Katz, A., Rozell, B., et al. (2007). Hypermetabolism in mice caused by the central action of an unliganded thyroid hormone receptor alphal. EMBO J. 26, 4535-4545. doi: 10.1038/sj.emboj.7601882

Smith, R. E., and Horwitz, B. A. (1969). Brown fat and thermogenesis. Physiol. Rev. 49, 330-425

Solymar, M., Petervari, E., Balasko, M., and Szelenyi, Z. (2015). The onset of daily torpor is regulated by the same low body mass in lean mice and in mice with diet-induced obesity. Temperature (Austin) 2, 129-134. doi: 10.1080/23328940.2015.1014250

Speakman, J. R. (2013). Measuring energy metabolism in the mouse theoretical, practical, and analytical considerations. Front. Physiol. 4:34. doi: 10.3389/fphys.2013.00034

Speakman, J. R., and Ward, S. (1998). Infrared thermography: principles and applications. Zool. Anal. Complex Systems 101, 224-232.

Stamp, J. A., and Herbert, J. (1999). Multiple immediate-early gene expression during physiological and endocrine adaptation to repeated stress. Neuroscience 94, 1313-1322. doi: 10.1016/S0306-4522(99)00368-1

Steiner, A. A., Chakravarty, S., Rudaya, A. Y., Herkenham, M., and Romanovsky, A. A. (2006). Bacterial lipopolysaccharide fever is initiated via Toll-like receptor 4 on hematopoietic cells. Blood 107, 4000-4002. doi: 10.1182/blood-2005-11-4743 
Steiner, A. A., Oliveira, D. L., Roberts, J. L., Petersen, S. R., and Romanovsky, A. A. (2008). Nicotine administration and withdrawal affect survival in systemic inflammation models. J. Appl. Physiol. 105, 1028-1034. doi: 10.1152/japplphysiol.90619.2008

Steiner, A. A., Turek, V. F., Almeida, M. C., Burmeister, J. J., Oliveira, D. L., Roberts, J. L., et al. (2007). Nonthermal activation of transient receptor potential vanilloid-1 channels in abdominal viscera tonically inhibits autonomic cold-defense effectors. J. Neurosci. 27, 7459-7468. doi: 10.1523/JNEUROSCI.1483-07.2007

Swoap, S. J. (2008). The pharmacology and molecular mechanisms underlying temperature regulation and torpor. Biochem. Pharmacol. 76, 817-824. doi: $10.1016 /$ j.bcp.2008.06.017

Szekely, M., and Szelenyi, Z. (1979). Endotoxin fever in the rat. Acta Physiol. Acad. Sci. Hung. 53, 265-277.

Szekely, M., Szelenyi, Z., and Sumegi, I. (1973). Brown adipose tissue as a source of heat during pyrogen-induced fever. Acta Physiol. Acad. Sci. Hung. 43, $85-88$.

Tschöp, M. H., Speakman, J. R., Arch, J. R., Auwerx, J., Bruning, J. C., Chan, L., et al. (2012). A guide to analysis of mouse energy metabolism. Nat. Methods 9, 57-63. doi: 10.1038/nmeth.1806

Vogel, B., Wagner, H., Gmoser, J., Worner, A., Loschberger, A., Peters, L., et al. (2016). Touch-free measurement of body temperature using close-up thermography of the ocular surface. MethodsX 3, 407-416. doi: 10.1016/j.mex.2016.05.002

Wang, Y., Kimura, K., Inokuma, K., Saito, M., Kontani, Y., Kobayashi, Y., et al. (2006). Potential contribution of vasoconstriction to suppression of heat loss and homeothermic regulation in UCP1-deficient mice. Pflugers Arch. 452, 363-369. doi: 10.1007/s00424-005-0036-3

Wanner, S. P., Garami, A., Pakai, E., Oliveira, D. L., Gavva, N. R., Coimbra, C. C., et al. (2012). Aging reverses the role of the transient receptor potential vanilloid-1 channel in systemic inflammation from anti-inflammatory to proinflammatory. Cell Cycle 11, 343-349. doi: 10.4161/cc.11.2.18772
Ward, C. S., Arvide, E. M., Huang, T. W., Yoo, J., Noebels, J. L., and Neul, J. L. (2011). MeCP2 is critical within HoxB1-derived tissues of mice for normal lifespan. J. Neurosci. 31, 10359-10370. doi: 10.1523/JNEUROSCI.0057-11.2011

Warner, A., and Mittag, J. (2014). Brown fat and vascular heat dissipation: the new cautionary tail. Adipocyte 3, 221-223. doi: 10.4161/adip.28815

Warner, A., Rahman, A., Solsjo, P., Gottschling, K., Davis, B., Vennstrom, B., et al. (2013). Inappropriate heat dissipation ignites brown fat thermogenesis in mice with a mutant thyroid hormone receptor alpha1. Proc. Natl. Acad. Sci. U.S.A. 110, 16241-16246. doi: 10.1073/pnas.1310300110

Willershäuser, M., Ehrhardt, N., Elvert, R., Wirth, E. K., Schweizer, U., GailusDurner, V., et al. (2012). "Systematic screening for mutant mouse lines with defects in body temperature regulation," in Living in a Seasonal World: Thermoregulatory and Metabolic Adaptations, eds T. Ruf, C. Bieber, W. Arnold, and E. Millesi (Berlin, Heidelberg: Springer-Verlag), 459-469.

Wither, R. G., Colic, S., Wu, C., Bardakjian, B. L., Zhang, L., and Eubanks, J. H. (2012). Daily rhythmic behaviors and thermoregulatory patterns are disrupted in adult female MeCP2-deficient mice. PLoS ONE 7:e35396. doi: 10.1371/journal.pone.0035396

Zethof, T. J., Van der Heyden, J. A., Tolboom, J. T., and Olivier, B. (1994). Stressinduced hyperthermia in mice: a methodological study. Physiol. Behav. 55 , 109-115. doi: 10.1016/0031-9384(94)90017-5

Conflict of Interest Statement: The authors declare that the research was conducted in the absence of any commercial or financial relationships that could be construed as a potential conflict of interest.

Copyright $(\odot 2017$ Meyer, Ootsuka and Romanovsky. This is an open-access article distributed under the terms of the Creative Commons Attribution License (CC BY). The use, distribution or reproduction in other forums is permitted, provided the original author(s) or licensor are credited and that the original publication in this journal is cited, in accordance with accepted academic practice. No use, distribution or reproduction is permitted which does not comply with these terms. 